\title{
Near-IR Absorbing BODIPY Derivatives as Glutathione-Activated Photosensitizers for Selective Photodynamic Action
}

\author{
Ilke Simsek Turan, ${ }^{[a]}$ Fatma Pir Cakmak, ${ }^{[b]}$ Deniz Cansen Yildirim, ${ }^{[c]}$ Rengul Cetin-Atalay, ${ }^{[c]}$ and \\ Engin U. Akkaya*[a, b]
}

\begin{abstract}
Enhanced spatiotemporal selectivity in photonic sensitization of dissolved molecular oxygen is an important target for improving the potential and the practical applications of photodynamic therapy. Considering the high intracellular glutathione concentrations within cancer cells, a series of BODIPY-based sensitizers that can generate cytotoxic singlet oxygen only after glutathione-mediated cleavage of the electron-sink module were designed and synthesized. Cell culture studies not only validate our design, but also suggest an additional role for the relatively hydrophobic quencher module in the internalization of the photosensitizer.
\end{abstract}

tosensitivity is still an issue, often leading to painful edema for patients undergoing PDT treatment. ${ }^{[4]}$ Thus, more selective PDT sensitizers are needed to remove any chance of off-target sensitization. In principle, this can be done in a number of ways. ${ }^{[5]}$ Previously, we reported a photosensitizer, the activity of which is dependent on the $\mathrm{pH}$ and ion concentrations. Other groups have reported quenched photosensitizers, by covalent attachments to carbon nanotubes, carotenoids, and the commercial quencher $\mathrm{BHQ}_{3}$. Self-quenching of the photosensitizer is another route for activity control.

The removal of quencher module can be accomplished enzymatically (by caspase 3 , cathepsin B, $\beta$-galactosidase, $\beta$-lactamase or trypsin, among others). Unfortunately, in most cases,
More than one hundred years after the initial observation of photodynamic action, ${ }^{[1]}$ generation of cytotoxic singlet oxygen by photosensitization of molecular oxygen through the intermediacy of a dye continues to attract considerable attention. ${ }^{[2]}$ This is mostly due to its medical applications, which is the photodynamic therapy (PDT) of various cancers and non-cancerous indications. ${ }^{[3]}$ One attractive feature of photodynamic therapy is in its built-in selectivity, which results from the fact that the exciting light can be targeted to the tumor region, thus minimizing accidental excitation of the sensitizer dye at undesired locations. In practice, however, pho-

[a] I. S. Turan, Prof. Dr. E. U. Akkaya

UNAM-Institute of Material Science and Nanotechnology

Bilkent University, Ankara, 06800 (Turkey)

E-mail:eua@fen.bilkent.edu.tr

[b] F. P. Cakmak, Prof. Dr. E. U. Akkaya

Department of Chemistry, Bilkent University, Ankara, 06800 (Turkey)

[c] D. C. Yildirim, R. Cetin-Atalay

Department of Molecular Biology and Genetics

Bilkent University, Ankara, 06800 (Turkey)

Supporting information for this article is available on the WWW under http://dx.doi.org/10.1002/chem.201405450.

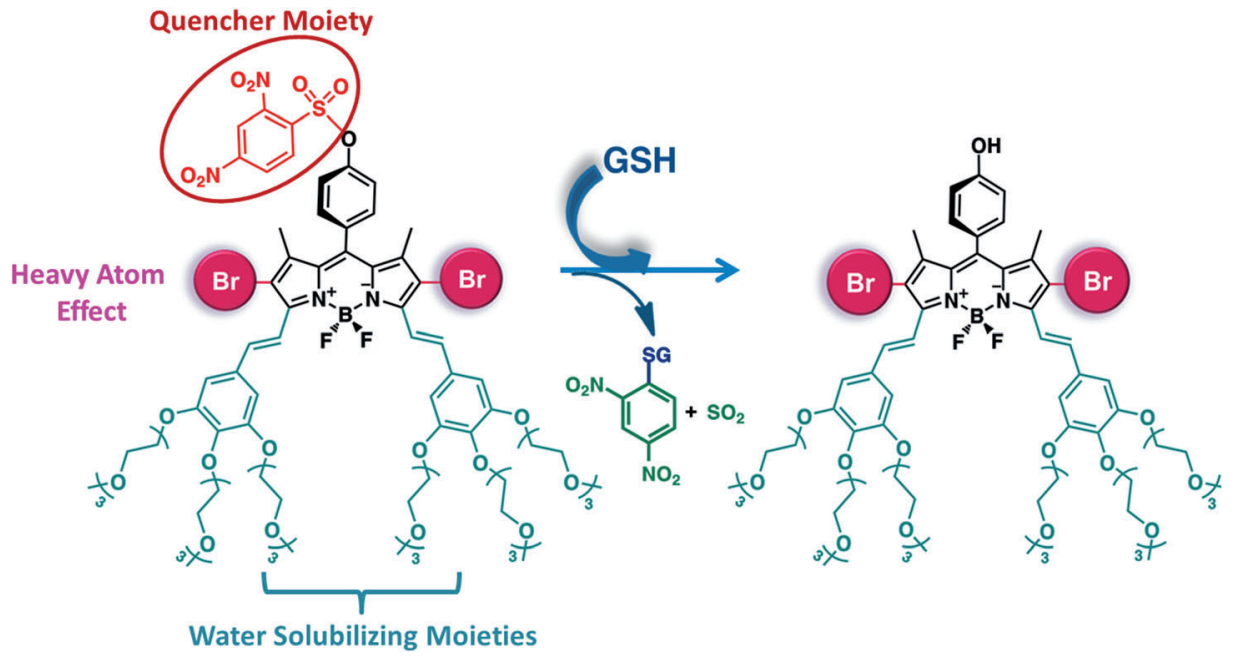

Figure 1. Mode of operation for the GSH-mediated activation of caged photosensitizers. the change in photosensitizer activity was less than tenfold. Our goal was to design a quenched photosensitizer, which is only capable of singlet oxygen generation after a glutathione (GSH)-mediated reaction that results in the removal of the quencher moiety (Figure 1). Such compounds could aptly be called "caged photosensitizers". It should also be noted here that cancer cells reportedly have much higher concentration of GSH (up to 1000-fold) compared with normal cells. ${ }^{[6]}$

To realize this goal, we set out to synthesize the target compounds depicted in Scheme 1 as caged sensitizers, to be released on a triggering GSH reaction. The design includes a 2,4dinitrobenzenesulfonate group, which was previously shown 


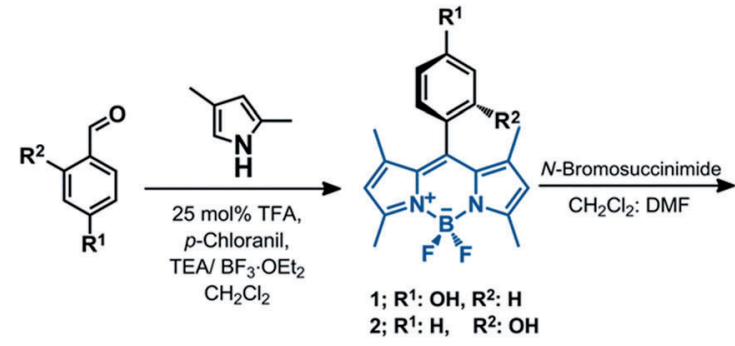

$\mathrm{Br}$
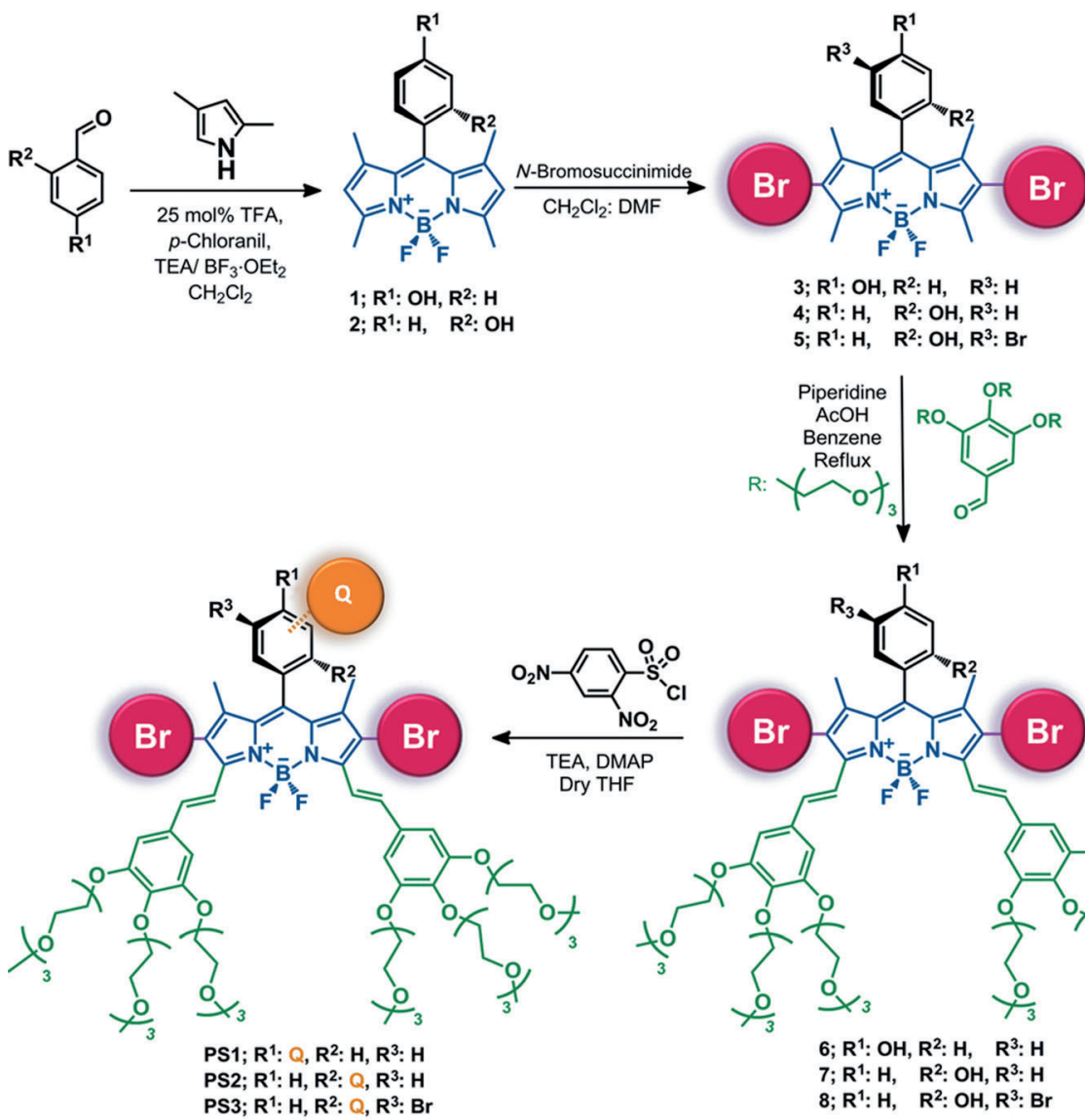

PS3; $R^{1}: H_{1} R^{2}$ : $Q^{3}, R^{3}$.

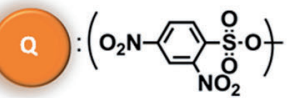

Scheme 1. Synthesis of the caged photosensitizers (PS1-3) and the control compounds (6-8). TFA=trifluoroacetic acid, TEA $=$ triethylamine, DMAP $=4$-dimethylaminopyridine.

to be susceptible to thiol mediated cleavage. ${ }^{[7]}$ The design can be abbreviated as PS-Q, Q being the electron sink 2,4-dinitrobenzenesulfonyl moiety, which quenches the excited state of the photosensitizer (PS) by providing an alternative, non-radiative relaxation path.

The core photosensitizer was based on the BODIPY chromophore, bromo or iodo-substituted derivatives of which have been shown on many occasions to be good candidates for photodynamic photosensitizers. ${ }^{[8]}$ The synthesis work was straightforward; hydroxyphenyl-BODIPY derivatives were synthesized, sulfonylated, and chromatographically purified. It is important to functionalize the dyes with heavy atoms to ensure an enhanced spin-orbit coupling, and thus faster rates of intersystem crossing (ISC), which in turn translates into more efficient singlet oxygen generation. BODIPY dyes without such modifications are known to be very poor photosensitizers unless they are arranged as orthogonal dimers. ${ }^{[8,9]}$ Oligoethyleneglycol moieties were added to improve the water solubility. Non-sulfonated BODIPY dyes 6-8 (meso-hydroxyphenylBODIPY derivatives) were utilized as control compounds for studying the change in activity in response to the removal of the dinitrobenzenesulfonate groups. All new compounds were characterized analytically. Once the synthesis and characterization were completed, we first studied the reaction with GSH spectroscopically.

Under physiological conditions, all three sulfonates can be cleaved at reasonable rates, a process that can be followed by spectral shifts in the electronic absorption spectra. In the cleavage reaction of PS1, the major band in the visible region shows a $35 \mathrm{~nm}$ blueshift (Figure $2 \mathrm{~A}$ ). Other photosensitizers also show such changes in the absorption. The cleavage of the quencher moiety can also be followed by the changes in the emission spectra. In $30 \mathrm{~min}$ more than $80 \%$ of the PS1 can be uncaged (see the Supporting Information). For the halogenated derivatives, intersystem crossing competes very effectively with the fluorescence emission process, resulting in low emission quantum yields.

Nevertheless, the quenching due to ISC is less than the essentially total quenching generated by the 2,4-dinitrobenzenesulfonyl moiety; thus, the emission enhanced at $683 \mathrm{~nm}$ is reported as another indication of the progress of the cleavage reaction (Figure $2 \mathrm{~B}$ ). As expected, the singlet oxygen generation capacity is nil when the quencher module $\mathrm{Q}$ is intact. But, when it is removed by the reaction with GSH, the residual BODIPY moieties are very effective in singlet oxygen generation (Figure 3). The change in the singlet oxygen generation capacity looks like an "off-on" process, demonstrating the effectiveness of the 2,4-dinitrophenyl moiety in quenching, and hence the "uncaging" process. So, it is clear that GSH at physiologically relevant concentrations is capable of transforming an ineffective chromophore into a very effective sensitizer that generates singlet oxygen when excited within the therapeutic window (in this case at $660 \mathrm{~nm}$ ).

Next, we wanted to demonstrate the effectiveness of intracellular GSH in activating our "caged" photosensitizers. To that end, a number of human epithelial cancer cells in culture (Huh7, MCF7, and HCT116) were tested with the photosensitizers, and as a control, photosensitizers with no quencher group (in other words, the active photosensitizers obtained when the $Q$ group is removed) were also included.

Based on our results with chemical trap studies of singlet oxygen generation, we expected higher photocytotoxic activity on cancer cells with the control series. The cell culture studies 

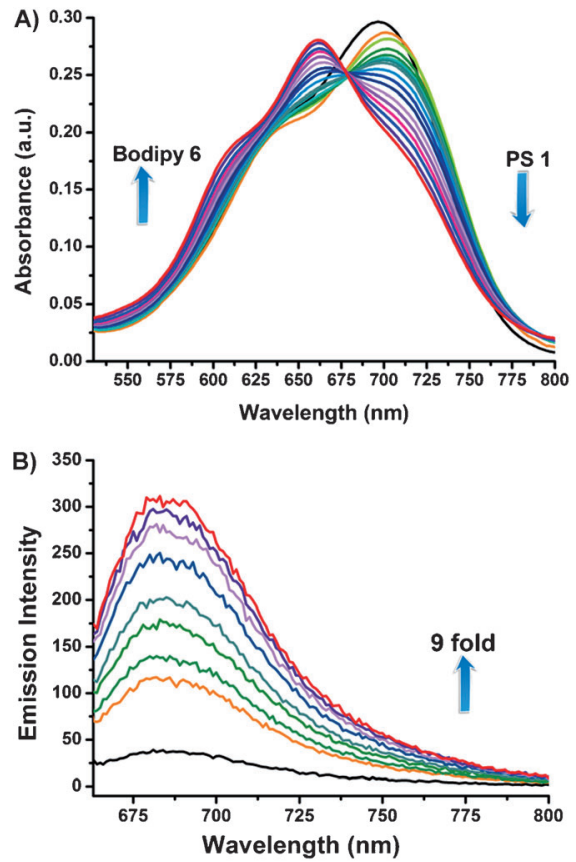

Figure 2. (A) Absorption spectra of PS1 $(20.0 \mu \mathrm{M})$, and (B) emission spectra of PS1 $(4.0 \mu \mathrm{M})$ upon addition of 50 equivalents of GSH in DMSO/1X PBS buffer (50:50, v/v, pH 7.4), inscribed for $120 \mathrm{~min}$. Excitation $\left(\lambda_{\mathrm{ex}}\right)$ is at $655 \mathrm{~nm}$. Corresponding data for PS2 and PS3 are available in the Supporting Information.

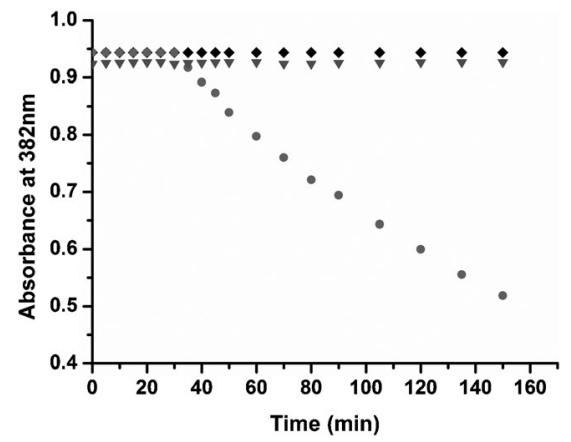

Figure 3. Absorbance values of the trap molecule $\left(2,2^{\prime}\right.$-(anthracene-9,10diyl)bis(methylene)dimalonic acid) in DMSO/1X PBS (50:50, v/v, pH: 7.4). BODIPY-6, or PS1 were introduced at $4 \mu \mathrm{M}$ concentration, except for the control run. Irradiation at $660 \mathrm{~nm}$ was initiated at $t=30 \mathrm{~min}$ ( $\mathbf{a}$ trap molecule alone, $\bullet$ BODIPY-6, $\nabla$ PS1). The light source was an LED array at $0.2 \mathrm{~mW}$ fluence rate.

were all done in triplicate with most of our caged photosensitizers were found to be effective. Some had relatively high dark toxicity, which was checked by additional experiments to isolate the contribution of photocytotoxicity.

The BODIPY dyes were tested both in the dark and under irradiation with red LED light. The results are presented in Table 1. In one particular colon cancer cell line, HCT116, we obtained a remarkable $\mathrm{IC}_{50}$ value of $20.0 \mathrm{~nm}$ under irradiation for PS1. The IC $C_{50}$ value without light is much higher, suggesting that much lower concentrations will be effective under the photodynamic regime.

\begin{tabular}{|lll|}
\hline \multicolumn{2}{|l|}{ Table 1. $\mathrm{IC}_{50}$ values of sensitizers with the $\mathrm{HCT} 116$ cell line. ${ }^{[\mathrm{a}]}$} \\
Sensitizers & Red LED irradiation for $4 \mathrm{~h}, \mathrm{IC}_{50}[\mu \mathrm{M}]$ & No light, $\mathrm{IC}_{50}[\mu \mathrm{M}]$ \\
\hline BODIPY-6 & $0.35 \pm 0.10$ & $0.35 \pm 0.16$ \\
BODIPY-7 & $0.64 \pm 0.11$ & $0.42 \pm 0.27$ \\
BODIPY-8 & $0.43 \pm 0.12$ & $0.75 \pm 0.04$ \\
BODIPY-11 & $0.04 \pm 0.02$ & $0.20 \pm 0.03$ \\
PS1 & $0.02 \pm 0.003$ & $4.38 \pm 0.03$ \\
PS2 & $0.02 \pm 0.004$ & $0.29 \pm 0.11$ \\
PS3 & $<0.06$ & $0.36 \pm 0.10$ \\
NC $^{[b]}$ & no inhibition & no inhibition \\
PS1 $^{[c]}$ & no inhibition & no inhibition
\end{tabular}

[a] IC 50 values of sensitizers with the HCT116 cell line after $72 \mathrm{~h}$ of incubation with indicated sensitizers. [b] NC: Negative control compound, 1,3,5,7-tetramethyl-BODIPY. [c] The effect of PS1 on MRC-5 human fetal lung fibroblast cells. The experiments were performed in triplicate.

It is both surprising and noteworthy that when control compounds (6-8) were introduced, we observed that their photocytotoxicity is significantly lower. This may be due to reduced cell permeability and lipid solubility. To investigate this matter further, we synthesized a putative positive control, compound 11 , where $\mathrm{R}^{1}=\mathrm{OCH}_{3}$ and $\mathrm{R}^{2}=\mathrm{R}^{3}=\mathrm{H}$. Control compound 11 is effective as a photosensitizer as predicted as it is unionizable and expected to be cell-permeable. Cellular uptake is an essential parameter for controlling the photocytotoxicity and even changes in the substitution pattern have an effect on intracelIular availability. ${ }^{[10]}$

However, it is clear that since the photosensitizers are in the caged form (PS-Q), they are not capable of producing singlet oxygen, but once the photosensitizers are inside the cells, intracellular GSH apparently cleaves the quencher module, and thus releases the active photosensitizer. Using fluorescence microscopy, (Figure 4) fluorescent-labeled Annexin-V and Hoechst-33258 co-staining show that cells clearly undergo apoptosis on irradiation in the presence of $20 \mathrm{~nm}$ of caged sensitizer PS1. This is demonstrated by the dense incorporation of the nuclear stain Hoechst-33258, and FITC-Annexin-V la-

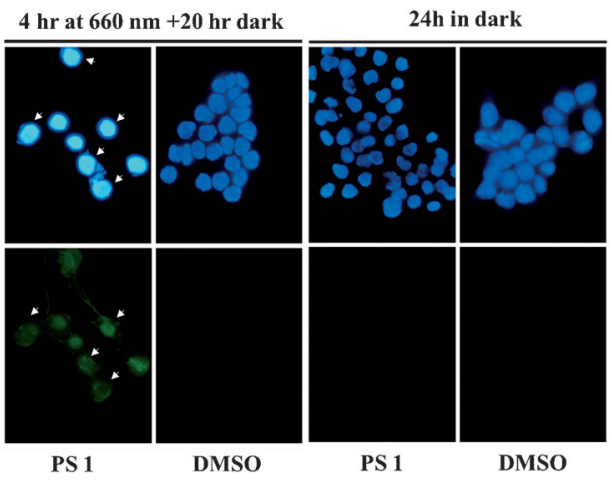

Figure 4. Fluorescence microscope images of Annexin-V-fluos stained HCT116 cells in the presence of $40 \mathrm{~nm}$ sensitizer 1 . Cells were either subjected to red LED irradiation at $660 \mathrm{~nm}$ for $4 \mathrm{~h}$, followed by $20 \mathrm{~h}$ incubation in the dark, or $24 \mathrm{~h}$ of incubation in dark. Hoechst-33258 stains nuclear DNA in all conditions. Arrows point to the apoptotic cells with fragmented chromatin (bright blue) and Annexin V positive membrane (green) corroborating apoptosis in the presence of light and PS1. Images were captured at $100 \times$ magnification. 
beling of the exposed phosphatidylserines on the outer cytoplasmic membrane. Without red light irradiation, cells show no such changes, keeping their usual appearance.

The response to the varying concentrations of the best performing sensitizers is also shown in the form of a bar graph (Figure 5).

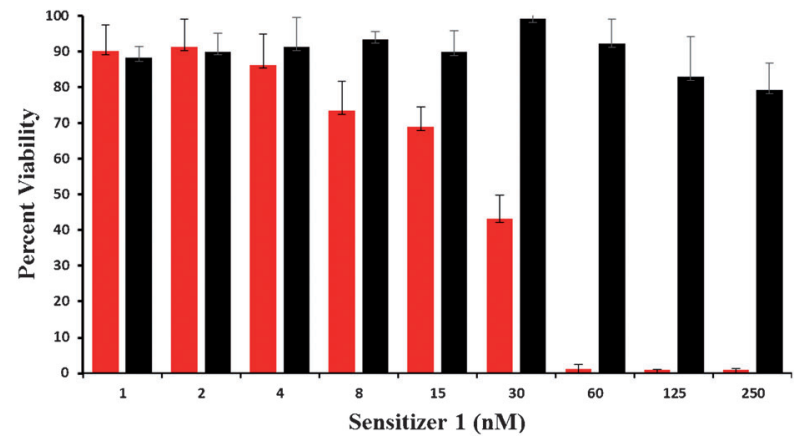

Figure 5. Percent viability of HCT116 cells was determined by NCI-SRB assay. Various concentrations of sensitizer PS1 (1-250 nM) were used to determine cell death. Red bars show cell viability after $4 \mathrm{~h}$ irradiation with red LED, followed by $20 \mathrm{~h}$ incubation in the dark, black bars indicate cell viability following $24 \mathrm{~h}$ incubation in the dark.

Additional support for PS1 inducing apoptosis in the HCT116 cell line was obtained by a fluorescence-activated cell sorting (FACS) analysis. The analysis shows that when the cells are treated with PS1 and red light, the percentage of cells with fractional (sub-G1) DNA content increase significantly compared with the control (Figure S20 in the Supporting Information).

Finally, we are very pleased that PS1 showed no apparent photocytotoxicity (or dark toxicity) on the MRC-5 (human fetal lung fibroblast cells) cell line, which is a normal cell line.

In conclusion, improved selectivity in any therapeutic agent is highly desirable. In this work, we took advantage of the activation (uncaging) of a photosensitizer by a cancer-related cellular parameter, glutathione concentration. Before the uncaging reaction, the $\mathrm{PS}-\mathrm{Q}$ conjugate has low to negligible toxic activity on the selected cell cultures. GSH-mediated intracellular uncaging results in a highly active photodynamic agent. We are confident that as the stumbling blocks hindering the broader applicability of photodynamic therapy are removed, the methodology will be more effective competitor of the current established treatment protocols. We shall continue to do our part in providing chemical/photophysical avenues towards that end.

\section{Experimental Section}

\section{Cell culture}

HCT116 human colon carcinoma cells (ATCC) were maintained in Dulbecco's Modified Eagle's Medium (DMEM) (Invitrogen GIBCO), with $10 \%$ fetal bovine serum (FBS) (Invitrogen GIBCO), glutamine $(2 \mathrm{~mm} \mathrm{~L})$, nonessential amino acids $(0.1 \mathrm{~mm})$, penicillin
(100 units $\left.\mathrm{mL}^{-1}\right)$, and streptomycin $\left(100 \mathrm{~g} \mathrm{~mL}^{-1}\right)$. MRC-5 human fetal lung fibroblast cells (ATCC) were maintained in Mininum Essential Medium (MEM) (Invitrogen GIBCO), with 10\% FBS (Invitrogen GIBCO), glutamine $(2 \mathrm{mML})$, penicillin $\left(100\right.$ units $\left.\mathrm{mL}^{-1}\right)$, and streptomycin $\left(100 \mathrm{~g} \mathrm{~mL}^{-1}\right)$ at $37^{\circ} \mathrm{C}$ in a humidified incubator under $5 \% \mathrm{CO}_{2}$.

\section{Sulforhodamine B assay}

Cells were plated in 96-well plates (2000 cell/well in $150 \mu \mathrm{L}$ ) and grown for $24 \mathrm{~h}$ at $37^{\circ} \mathrm{C}$ prior to treatment with different concentrations of sensitizers and negative control $(0.25-0.0005 \mu \mathrm{M}$ for sensitizers 1,2 , and $3 ; 5.0-0.06 \mu \mathrm{M}$ for BODIPYs dissolved in DMSO). After $72 \mathrm{~h}$ of incubation, the medium was aspirated, washed once with 1X PBS (Gibco, Invitrogen), followed by addition of $50 \mu \mathrm{L}$ of a cold $\left(4^{\circ} \mathrm{C}\right)$ solution of $10 \%(\mathrm{v} / \mathrm{v})$ trichloroacetic acid (MERCK) for fixation. Then the plates were washed five times with $d d-\mathrm{H}_{2} \mathrm{O}$ and were left to air-dry. A solution of sulforhodamine $(50 \mu \mathrm{L}, 0.4 \%$, $\mathrm{m} / \mathrm{v}$; Sigma-Aldrich) in $1 \%$ acetic acid solution was then added to each well and left at room temperature for $10 \mathrm{~min}$. The sulforhodamine B (SRB) solution was removed and the plates were washed five times with $1 \%$ acetic acid and left for air-drying. Proteinbound sulforhodamine $B$ was solubilized in a Tris-base solution $(200 \mu \mathrm{L}, 10 \mathrm{~mm})$ and the plates were shaken for $10 \mathrm{~min}$ on a plate shaker before the measurement of absorbance. The absorbance was read in a 96-well plate reader at $515 \mathrm{~nm}$. Cells incubated in DMSO alone were used as controls for percent inhibition and $\mathrm{IC}_{50}$ calculations either in irradiated plates (for $4 \mathrm{~h}$ ) or the plates kept in dark. Percent inhibition (\%) values were calculated with the given formula: 1-[average (OD of treated wells)/average (OD of DMSO treated cells)] $\times 100$.

\section{Detection of apoptosis}

Cells were seeded onto coverslips in 6-well plates. After $24 \mathrm{~h}$ in culture, cells were treated with sensitizer 1 ( $40 \mathrm{~nm} /$ well). One group was irradiated with red LED at $625 \mathrm{~nm}$ for $4 \mathrm{~h}$ and kept $20 \mathrm{~h}$ in the dark. Another group was incubated in the dark for $24 \mathrm{~h}$. Apoptosis was determined with Annexin-V-Fluos (Roche) staining together with Hoechst-33258 (Sigma-Aldrich) counterstaining that shows the nuclear condensation. Cells were washed twice with ice-cold 1X PBS. Hoechts-33258 staining was performed with $1 \mu \mathrm{g} \mathrm{mL}^{-1}$ (final concentration) in each well followed by incubation for $10 \mathrm{~min}$ in the dark. Cells were destained with $1 \mathrm{X}$ PBS for $5 \mathrm{~min}$. Then, Annexin-V-Fluos staining was carried out according to the manufacturer's recommendations (Roche). Slides were then analyzed under the fluorescence microscope (Nikon Eclipse 50i).

\section{Acknowledgements}

The authors gratefully acknowledge support from TUBITAK in the form of a grant (112T480).

Keywords: BODIPY dyes · photochemistry · photodynamic action $\cdot$ photosensitizers $\cdot$ singlet oxygen

[1] a) O. Raab, Z. Biol. 1900, 39, 524-546; b) A. Jesionek, H. von Tappeiner, MMW Muench. Med. Wochenschr. 1903, 47, 2042-2044; c) H. von Tappeiner, A. Jodlbauer, Dtsch. Arch. Klin. Med. 1904, 80, 427-487.

[2] a) A. Kamkaew, S. H. Lim, H. B. Lee, L. V. Kiew, L. Y. Chung, K. Burgess, Chem. Soc. Rev. 2013, 42, 77-88; b) A. B. Ormond, H. S. Freeman, Materials 2013, 6, 817-840; c) O. J. Stacey, S. J. A. Pope, RSC Adv. 2013, 3, 25550-25564; d) S. G. Awuah, Y. You, RSC Adv. 2012, 2, 11169-11183. 
[3] a) W. M. Gallagher, L. T. Allen, C. O'Shea, T. Kenna, M. Hall, A. Gorman, J. Killoran, D. F. O'Shea, Br. J. Cancer 2005, 92, 1702-1710; b) S. G. Rock son, P. Kramer, M. Razavi, A. Szuba, S. Filardo, P. Fitzgerald, J. P. Cooke S. Yousuf, A. R. DeVault, M. F. Renschler, D. C. Adelman, Circulation 2000 102, 2322-2324; c) D. E. J. G. J. Dolmans, D. Fukurama, R. K. Jain, Nat Rev. Cancer 2003, 3, 380-387; d) R. Waksman, P. E. McEwan, T. I. M Moore, R. Pakala, F. D. Kolodgie, D. G. Hellinga, R. C. Seabron, S. J. Rychnovsky, J. Vasek, R. W. Scott, R. Virmani, J. Am. Coll. Cardiol. 2008, 52, 1024-1032; e) Y. Choi, R. Weissleder, C.-H. Tung, Cancer Res. 2006, 66, 7225-7229; f) T. J. Dougherty, C. J. Gomer, B. W. Henderson, G. Jori, D. Kessel, M. Korbelik, J. Moan, Q. Peng, J. Natl. Cancer Inst. 1998, 90, 889905; g) T. J. Dougherty, J. E. Kaufman, A. Goldfarb, K. R. Weishaupt, D. Boyle, A. Mittleman, Cancer Res. 1978, 38, 2628-2635.

[4] a) J. Gołab, D. Olszewska, P. Mróz, K. Kozar, R. Kamiński, A. Jalili, M. Jakóbisiak, Clin. Cancer Res. 2002, 8, 1265-1270; b) H. Hirschberg, F. A. Uzal, D. Chighvinadze, M. J. Zhang, Q. Peng, S. J. Madsen, Lasers Surg. Med. 2008, 40, 535-542; c) M. S. Mathews, D. Chighvinadze, H. M. Gach, F. A Uzal, S. J. Madsen, H. Hirschberg, Lasers Surg. Med. 2011, 43, 892-900.

[5] a) S. Ozlem, E. U. Akkaya, J. Am. Chem. Soc. 2009, 131, 48-49; b) S. Erbas, A. Gorgulu, M. Kocakusakogulları, E. U. Akkaya, Chem. Commun. 2009, 4956-4958; c) S. O. Mcdonnell, M. J. Hall, L. T. Allen, A. Byrne, W. M. Gallagher, D. F. O'Shea, J. Am. Chem. Soc. 2005, 127, 1636016361 ; d) J. Chen, K. Stefflova, M. J. Niedre, B. C. Wilson, B. Chance, J. D. Glickson, G. Zheng, J. Am. Chem. Soc. 2004, 126, 11450-11451; e) G. Zheng, J. Chen, K. Stefflova, M. Jarvi, H. Li, B. C. Wilson, Proc. Natl. Acad. Sci. USA 2007, 104, 8989-8994; f) T. Yogo, Y. Urano, A. Mizusmus, H. Sunahara, T. Inoue, K. Hirose, M. Lino, K. Kikuchi, T. Nagano, Proc. Natl. Acad. Sci. USA 2008, 105, 28-32.

[6] a) Z.-B. Zheng, G. Zhu, H. Tak, E. Joseph, J. L. Eiseman, D. J. Creighton, Bioconjugate Chem. 2005, 16, 598-607; b) H. S. Jung, X. Chen, K. Seung, J. Yoon, Chem. Soc. Rev. 2013, 42, 6019-6031; c) C.-C. Yeh, M.-F. Hou, S.H. Wu, S.-M. Tsai, S.-K. Lin, L. A. Hou, H. Ma, L. Y. Tsai, Cell Biochem. Funct. 2006, 24, 555-559; d) S. C. Barranco, R. R. Perry, M. E. Durm, M. Quarishi, A. L. Werner, S. G. Gregorcyk, P. Kolm, Dis. Colon Rectum 2000, 43, $1133-1140$.

[7] a) S. Ji, H. Guo, X. Yuan, X. Li, H. Ding, P. Gao, C. Zhao, W. Wu, W. Wu, J. Zhao, Org. Lett. 2010, 12, 2876-2879; b) J. Shao, H. Guo, S. Ji, J. Zhao, Biosens. Bioelectron. 2011, 26, 3012-3017; c) J. Ålander, K. Johansson, V. D. Heuser, H. Farebo, J. Järvliden, H. Abe, A. Shibata, M. Ito, Y. Ito, R.
Morgenstern, Anal. Biochem. 2009, 390, 52-56; d) A. Shibata, K. Furukawa, H. Abe, S. Tsuneda, Y. Ito, Bioorg. Med. Chem. Lett. 2008, 18, $2246-$ 2248; e) H. Maeda, H. Matsuno, M. Ushida, K. Katayama, K. Saeki, N. Itoh, Angew. Chem. 2005, 117, 2982-2985; Angew. Chem. Int. Ed. 2005, 44, 2922-2925; f) W. Jiang, Q. Fu, H. Fan, J. Ho, W. Wang, Angew. Chem. 2007, 119, 8597-8600; Angew. Chem. Int. Ed. 2007, 46, 8445-8448; g) X. Li, S. Qian, Q. He, B. Yang, J. Li, Y. Hu, Org. Biomol. Chem. 2010, 8 3627-3630; h) Z. Dai, L. Tian, Z. Ye, B. Song, R. Zang, J. Yuan, Anal. Chem. 2013, 85, 11658-11664; i) K. Cui, Z. Chen, Z. Wang, G. Zhang, D. Zhang, Analyst 2011, 136, $191-195$; j) S.-Q. Wang, Q.-H. Wu, H.-Y. Wang, X.-X. Zheng, S.-L. Shen, Y.-R. Zhang, J.-Y. Miao, B.-X. Zhao, Analyst 2013, 138, 7169-7174; k) H. Guo, Y. Jing, X. Yuan, S. Ji, J. Zhao, X. Li, Y. Kan, Org. Biomol. Chem. 2011, 9, 3844-3853; I) H. He, P.-C. Lo, D. K. P. Ng, Chem. Eur. J. 2014, 20, 6241-6245.

[8] a) S. Atilgan, Z. Ekmekci, A. L. Dogan, D. Guc, E. U. Akkaya, Chem. Commun. 2006, 4398-4400; b) Y. Cakmak, S. Kolemen, S. Duman, Y. Dede, Y. Dolen, B. Kilic, Z. Kostereli, L. T. Yildirim, A. L. Dogan, D. Guc, E. U. Akkaya, Angew. Chem. 2011, 123, 12143-12147; Angew. Chem. Int Ed. 2011, 50, 11937-11941; c) M. Isik, T. Ozdemir, I. S. Turan, S. Kolemen, E. U. Akkaya, Org. Lett. 2013, 15, 216-219; d) T. Yogo, Y. Urano, Y. Ishitsuka, F. Maniwa, T. Nagano, J. Am. Chem. Soc. 2005, 127, $12162-12163$ e) X. Zhang, Y. Xiao, J. Qi, J. Qu, B. Kim, X. Yue, K. D. Belfield, J. Org. Chem. 2013, 78, 9153-9160; f) H. Yu, Y. Dai, H. Lib, Y. Xiao, New J. Chem. 2013, 37, 1688-1691; g) S. Kou, H. N. L. Lee, D. van Noort, K. M. K. Swamy, S. H. Kim, J. H. Soh, K.-M. Lee, S.-W. Nam, J. Yoon, S. Park Angew. Chem. 2008, 120, 886-890; Angew. Chem. Int. Ed. 2008, 47, $872-876$; h) L. Li, J. Han, B. Nguyen, K. Burgess, J. Org. Chem. 2008, 73, 1963-1970; i) G. Ulrich, R. Ziessel, A. Harriman, Angew. Chem. 2008, 120, 1202-1219; Angew. Chem. Int. Ed. 2008, 47, 1184-1201.

[9] a) W. Pang, X.-F. Zhang, J. Zhou, C. Yu, E. Hao, L. Jiao, Chem. Commun. 2012, 48, 5437-5439; b) X.-F. Zhang, X. Yang, J. Phys. Chem. B 2013, $117,9050-9055$.

[10] Y. You, S. L. Gibson, R. Hilf, S. R. Davies, A. R. Oseroff, I. Roy, T. Y. Ohulchanskyy, E. J. Bergy, M. E. Detty, J. Med. Chem. 2003, 46, 3734-3747.

Received: September 28, 2014

Published online on October 24, 2014 